\title{
Relationships between quality of life and family function in caregiver
}

\author{
Emiliano Rodríguez-Sánchez ${ }^{1 *}$, Aníbal Pérez-Peñaranda ${ }^{1,2+}$, Andrés Losada-Baltar ${ }^{3+}$, Diana Pérez-Arechaederra ${ }^{1+}$, \\ Manuel Á Gómez-Marcos ${ }^{1+}$, Maria C Patino-Alonso ${ }^{1,4 \dagger}$ and Luís García-Ortiz ${ }^{1+}$
}

\begin{abstract}
Background: There are caregivers who see their quality of life (QoL) impaired due to the demands of their caregiving tasks, while others manage to adapt and overcome the crises successfully. The influence of the family function in the main caregiver's situation has not been the subject of much evaluation. The aim of this study is to analyse the relationship between the functionality of the family and the QoL of caregivers of dependent relatives.

Methods: We conducted a cross-sectional study including 153 caregivers. Setting: Two health centers in the city of Salamanca(Spain). Caregiver variables analysed: demographic characteristics, care recipient features; family functionality (Family APGAR-Q) and QoL (Ruiz-Baca-Q) perceived by the caregiver. Five multiple regressions are performed considering global QoL and each of the four QoL dimensions as dependent variables. The Canonical Correspondence Analysis (CCA) was used to study the influence of the family function questionnaire on QoL.
\end{abstract}

Results: Family function is the only one of the variables evaluated that presented an association both with global QoL and with each of the four individual dimensions $(p<0.05)$. Using the CCA, we found that the physical and mental well-being dimensions are the ones which present a closer relationship with family functionality, while social support is the quality dimension that is least influenced by the Family APGAR-Q.

Conclusion: We find an association between family functionality and the caregiver's QoL. This relation holds for both the global measure of QoL and each of its four individual dimensions.

\section{Background}

Disease and incapacity are common experiences that represent one of the greatest challenges for families, since the psychosocial problems occasioned by a person with dependence have an impact on the whole family system. In these family contexts many families suffer a deterioration in their quality of life (QoL), while others manage to adapt and overcome the crisis successfully [1-4].

Functional families are those in which the roles of all the members are laid down without critical points of assumed debilities and without positions of either artificial or assumed supremacy being held by any of the members and in which they all participate, work, contribute and cooperate on an equal basis and with

\footnotetext{
* Correspondence: emilianorodriguezsanchez@yahoo.es

† Contributed equally

'Unidad de investigación del Centro de Salud de La Alamedilla. Salamanca. España

Full list of author information is available at the end of the article
}

enthusiasm for the collective welfare. Sometimes several members of the family take care of the dependent relative, but it is more common for the burden of the care to lie with a single person: the main caregiver $[1,5,6]$. This care affects the caregiver significantly in physical, mental, social and economic aspects. It produces an overload of tasks and it usually changes the functional dynamics of the family [6-9].

Although at this time there is a movement aimed at the study of the patient's quality of life, it underscores the importance of the caregiver's view [10], the fact of the matter is that is important to consider the quality of life of the family members responsible for the care of patients in a situation of dependence as to consider the QoL of the dependent himself/herself [1,4]. Quality of life is a global health indicator that provides information not supplied in the clinical instruments normally used, giving information on the physical, psychological and social dimensions of people's life $[1,4,11,12]$.

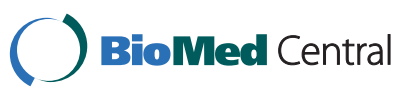


The aim of this study is to analyse the influence of the functionality of the family in the QoL of the caregivers of family dependents and to determine the variables related to both dimensions.

\section{Methods}

We conducted a cross-sectional study in two urban primary care health centres. Health professionals of both centres contacted 174 caregivers who provided their dependent relatives the main assistance for their basic daily life activities (BDLA). Those persons who did not share their place of residence with the relative, or who were impossible to locate either due to a change of address or being admitted to hospital or a nursing home, or on account of the patient's death, were excluded. At the end 153 caregivers were included.

The study was approved by the research ethics committee from health area of Salamanca, complies with Spanish data protection law 15/1999 and its recently developed specifications (Royal Decree (RD) 1720/2007) and all the subjects who took part in the study signed the informed consent form prior to their inclusion.

\section{Measures}

The data were collected by means of a home interview to the caregivers and the dependent relatives by a psychologist and two nurses with prior training to apply the questionnaires. Variables related to the caregiver: a) Demographic characteristics (age, gender, marital status, educational level, occupation, relationship, age at the start of caregiving), hours of attention per day and months of caregiver. b) Family functionality perceived by the caregiver was evaluated with the Family APGAR Questionnaire (APGARq) validated in Spain [13]. This questionnaire rates satisfaction with family relations and distinguish five components of the family function: adaptability, partnership, growth, affection and resolve. It consists in five questions shown in Table 1, with three possible answers: 0 ("hardly ever"), 1 ("sometimes"), 2 ("always"). The total score range varies from 0 to 10 , meaning the higher total score, the better family functioning. A global score of 7 points or more indicates family functionality, while a score of less than 7 points indicates family dysfunction. The internal consistency of this questionnaire in this study was 0.77 . c) Quality of life was evaluated with Ruiz-Baca's Questionnaire (1993) [14]. This is made up of 39 items each with a Likert-type five-point scale comprising four dimensions: social support, general satisfaction, physi$\mathrm{cal} / \mathrm{mental}$ well-being, work overload and free time $($ Cronbach's alpha $=0.94)$. Variables related to the dependent relative: a) Demographic characteristics (age, gender, education.); b) Cognitive status: the possible existence of cognitive deterioration in the care recipient is assessed with Pfeiffer's Test (Cronbach's alpha = 0.94) [15]. c) The functional capacity of the patients was assessed with Barthel's index [16], which evaluates the person's capacity to perform different BDLA (Cronbach's alpha $=0.91)$.

\section{Analysis}

We performed a chi-square test to establish the relation between independent qualitative variables, Student's ttest to evaluate the relation between two-category qualitative and quantitative variables, and correlation for the quantitative variables. Five multiple regressions were performed, considering the global QoL and each of the four dimensions of the QoL questionnaire (social support, general satisfaction, physical/mental well-being, and absence of work overload/free time). In each of the analyses the same explanatory variables are used for the caregiver (caregiver's gender, occupation and age, age at the start of the caregiving, care hours/day, caregiver's time, caregiver's educational level) and for the dependent relative (gender, age and educational level). While the caregiver's gender and the patient's gender remain fixed in the regression model, the stepwise method is applied to the rest of the variables. In order to study the influence that each item of the APGARq has on the QoL of the caregivers, the Canonical Correspondence Analysis (CCA), proposed by Braak, was used [17]. The starting point is two matrices, one containing the

Table 1 Matrix used for the Canonical Correspondence Analysis (ACC) (Ter Braak, 1988)

\begin{tabular}{|c|c|}
\hline $\begin{array}{c}\text { QUALITY OF LIFE ÍTEMS: } \\
\text { DIMENSIONS OF THE PERCEIVED QUALITY OF LIFE AND CARE OF PATIENTS } \\
\text { QUESTIONAIRE (RUíZ Y BACA, 1993) }\end{array}$ & $\begin{array}{l}\text { FAMILY ASSESSMENT ÍTEMS: } \\
\text { FAMILY APGAR ITEMS }\end{array}$ \\
\hline $\begin{array}{c}\text { - Social support } \\
\text { - General Satisfaction } \\
\text { - Physical and Mental Wellness } \\
\text { - Lack of work overload/free time }\end{array}$ & $\begin{array}{c}\text { SAF: Are you satisfied with the help that you received from } \\
\text { your family? } \\
\text { CPF: Do you talk with your family about your household } \\
\text { problems? } \\
\text { SQF: Do you feel that your family loves you? } \\
\text { STF: Are you satisfied with the time that you and your family } \\
\text { share together? } \\
\text { DIF: Do you discuss with your family about important decisions } \\
\text { that affect the whole family? }\end{array}$ \\
\hline
\end{tabular}


information for the 153 subjects under study, relating to the items of the dimensions of the Ruíz-Baca Questionnaire QoL, and a second matrix containing the information of the APGARq items relating to the family function (Table 1). The family function items are represented by vectors, which are constructed by joining the point represented by the item with the centre of gravity of the HyperCloud projected on the subspace of maximum inertia. The angle that the respective items evaluating the different aspects of the family function form between one another allows us to estimate the degree of covariation between the different aspects. To evaluate the influence that a given item of family function has on each of the aspects of QoL, we merely draw the perpendicular to the vector joining the family function item with the origin of coordinates. The points representing the different aspects of QoL whose projection of the family function variable vector lie closer to the tip of the arrow tell us which have higher values in relation to this variable. Accepting an alpha risk of 0.05 and a beta risk of 0.05 in a two-sided test, with 46 subjects in first group (dysfunctional family) and 107 in the second (functional family) and common standard deviation of 0.67 is enough to recognize as statistically significant a difference greater or equal than 0.43 units of mean global QoL. The program used for the processing and analysis of the data was SPSS/PC+ (V.15.0), except for the CCA, where the Canoco 4.5 for Windows package was used [18-20].

\section{Results}

Sociodemographic data for the resulting sample and the descriptive statistics for the assessed variables are shown in Table 2. In Table 3 we observe the APGARq results, with a global mean score of 1.52 (scale 0-2), with the highest rated item being "feels that his/her family loves him/her" (SQF)(1.78). A 69.93\% of the families were in a situation of normal functionality ( $\geq 7$ points).

The global QoL score obtained for the total sample was 3.25 (scale 1-5). The normofunctional families have a QoL mean score of 3.84 (SD: 0.60) and the dysfunctional ones 2.87 (SD: 0.65) ( $\mathrm{p}<0.05)$. In its multidimensional character, QoL showed the best score in perceived social support (3.63), whereas work overload and lack of free time (2.78) were the dimensions that showed greater deterioration.

\section{Multiple linear regression analysis of QoL}

In Table 4 we present the variables included in the equation Global QoL and its dimensions as dependent variables, adjusted by caregiver's and the patient's gender. In the multiple linear regression, taking the global QoL as the dependent variable, family function (beta = 0.139 ) and to be spouse (beta $=-0.461$ ) remained in the equation. In the multiple linear regression of the different dimensions of quality of life, the family function remained always in the equation. In the social support dimension, to be a grandchild (beta $=0.857$ ) and a son/ daughter (beta $=0.464$ ) remained also in the equation; and the lack of overload dimension remained to be spouse (beta $=-0.607)$, cognitive deterioration (beta $=$ 0.367 ) and level of functional dependence (beta = $-0.409)$.

\section{Canonical Correspondence Analysis (CCA)}

The ordination diagram for the influence that the individual items of the APGARq have on the quality of life of the caregivers, using CCA, can be seen in Figure 1. Special mention should be made regarding the small angle formed between the variables "Are you satisfied with the help you receive from your family?" (SAF) and "Are important decisions made jointly at home?" (DIF), which indicates a high correlation between these aspects. This may be interpreted as that those caregivers who make the important decisions with their family are satisfied with the help that they receive from them. For the items "Are you satisfied with the time that your family and you spend together?" (STF) and SQF, we found a similar interpretation (i.e. those who spend time with their families feel that their families love them). Furthermore, special mention should be made of the independence between items SAF and STF.

In Figure 1 we observe how the dimension relative to social support was the dimension that appears to be less influenced by the family function items. The dimension absence of work overload and free time marks the upper end of the gradient for the variable SAF, so we may interpret that those caregivers who have absence of work overload and free time are satisfied with the help that they receive from their family. In a similar way, we observe how, if we project the dimension relating to Physical and mental well-being on SAF, DIF, CPF, SQF and STF, it marks the upper end of the gradient in all of them. This means that for a caregiver to be able to have a good state of physical and mental well-being, he or she has to be satisfied with the help received from his or her family, converse with them, feel the affection of his or her family, be satisfied with the time that his or her family spend with him or her, and make family decisions.

\section{Discussion}

This study shows the relationship between family functionality and the caregiver's QoL. According to these results, this relationship is found both for the global measure of QoL and for each of the four dimensions of this variable. While the dimension relating to physical and mental well-being is the one that presents a closer 
Table 2 Demographic characteristics of the caregivers and of the patients studied

\begin{tabular}{|c|c|c|c|}
\hline \multicolumn{2}{|l|}{ Caregivers } & \multicolumn{2}{|c|}{ Dependent Patients } \\
\hline \multicolumn{2}{|l|}{ Age (years) } & \multicolumn{2}{|c|}{ Age (years) } \\
\hline Global $(\mathrm{n}=153$ ) & $63.8 \pm 12.8$ & Global $(\mathrm{n}=153)$ & $79.14 \pm 17.3$ \\
\hline Males $(n=42)$ & $66.8 \pm 13.6$ & Males $(n=48)$ & $74.90 \pm 19$ \\
\hline Females $(\mathrm{n}=111)$ & $62.7 \pm 12.4$ & Females $(\mathrm{n}=105$ & $81.08 \pm 15.9$ \\
\hline Age when they started being caregivers & $53.0 \pm 13.9$ & & \\
\hline Hours per day caring for & $19.2(7.2)$ & & \\
\hline \multicolumn{2}{|l|}{ Marital status } & \multicolumn{2}{|c|}{ Level of functional dependence ${ }^{a}$} \\
\hline Married & $99(64.7 \%)$ & Total & $76(49.7 \%)$ \\
\hline Single & $42(27.5 \%)$ & Severe & $28(18.3 \%)$ \\
\hline \multirow[t]{2}{*}{ Widow } & $12(7.8 \%)$ & Moderate & $32(20.9 \%)$ \\
\hline & & slight & $17(11 \%)$ \\
\hline \multicolumn{2}{|l|}{ Level of Education } & \multicolumn{2}{|c|}{ Level of Education } \\
\hline Graduate & $25(16.3 \%)$ & Graduate & $0(0.0 \%)$ \\
\hline Secondary studies & $29(19.0 \%)$ & Secondary studies & $11(7.2 \%)$ \\
\hline Primary studies & $88(57.5 \%)$ & Primary Studies & $107(69.9 \%)$ \\
\hline Illiterate & $11(7.2 \%)$ & Illiterate & $20(13.1 \%)$ \\
\hline Non answered & $0(0.0 \%)$ & Non answered & $15(9.8 \%)$ \\
\hline \multicolumn{2}{|c|}{ Relationship with the dependent } & \multicolumn{2}{|c|}{ Cognitive damage $^{b}$} \\
\hline Son/daughter & $72(47.1 \%)$ & Important & $63(41.2 \%)$ \\
\hline Spouse & $41(26.8 \%)$ & Moderate & $26(17.0 \%)$ \\
\hline Parents & $22(14.4 \%)$ & slight & $14(9.2 \%)$ \\
\hline Others & $18(11.9 \%)$ & Without damage & $50(32.7 \%)$ \\
\hline \multicolumn{4}{|l|}{ Activities : } \\
\hline Housewife and caregiver & $115(75.2 \%)$ & & \\
\hline Worker and caregiver & $33(21.6 \%)$ & & \\
\hline Other & $5(3.3 \%)$ & & \\
\hline
\end{tabular}

The data are presented as the Mean \pm Standard Deviation or as number and percentage.

a.- Assessment of the level of functional dependence according to Barthel categorization: Total dependence: Value 0-20; Severe dependence: 21-60; Moderate dependence: 61-90; Slight dependence: 91-99; Independent: 100 .

b.-Cognitive damage assessed with Pfeiffer's measure: Severe damage: 8-10 errors; Moderate: 5-7; Slight: 3-4; Without damage: $0-3$.

relationship with family functionality, social support is the dimension that seems to be less influenced by the family function items.

The Family APGAR test and the Ruiz-Baca QoL test results suggest that caregivers' perceived physical and mental well-being is related with being satisfied with the help received from their family, conversing with their relatives, feeling the affection of their family, being satisfied with the time that their family spends with them, and making family decisions. Providing support for caregivers or relieving the situations of work overload and stress that they are suffering may not br enough. These results indicate that it is important to ensure that when caregivers receive support, they actually perceive it like that, expressing their improvement at both the physical and emotional level.

There are caregivers of family dependents who present extremely different levels of QoL in similar circumstances [1-3]. The results of this study suggest that family function plays a particularly important role when it comes to explaining the QoL of the caregivers. This study adds to previous studies, in which the role of family functionality has been shown in the stress process in dementia patient caregivers [21,22], the significant capacity of this variable in explaining QoL. We consider that family function affects not only those who are caring for relatives with dementia, but also has an impact on caregivers of dependents with a wide range of medical conditions, like those included in this study.

In these study we found that the perception of QoL shown by caregivers differs according to the degree of kinship: only in children and grandchildren we found a positive correlation with social support [23]. This fact was even more significant upon observing that being the spouse correlates negatively both in global QoL and in the three dimensions other than social support. Neither family function nor QoL seem to have a significant correlation with the sociodemographic or educational level variables of caregivers according to the obtained results, which contrasts with findings from other studies [24,25]. 
Table 3 Family functioning assessment with the Family-APGAR and quality of life assessment with Ruiz and Baca's questionnaire

\begin{tabular}{|c|c|c|}
\hline Family APGAR Questionnaire ${ }^{a}$ & Mean & $\pm S D$ \\
\hline Family function APGAR (global mean) & 1.52 & 0.46 \\
\hline 1. Are you satisfied with the help that you received from your family? & 1.42 & 0.67 \\
\hline 2. Do you talk with your family about your household problems? & 1.49 & 0.61 \\
\hline 3. Do you feel that your family loves you? & 1.78 & 0.49 \\
\hline 4. Are you satisfied with the time that you and your family share together? & 1.50 & 0.64 \\
\hline 5. Do you discuss with your family about important decisions that affect the whole family? & 1.41 & 0.74 \\
\hline Caregivers with a functional family ${ }^{\mathrm{b}} \mathrm{n}(\%)$ & \multicolumn{2}{|c|}{$107(69.93 \%)$} \\
\hline Quality of life dimensions ${ }^{c}$ & Mean & $\pm \mathrm{SD}$ \\
\hline Global perceived quality of life & 3.25 & 0.67 \\
\hline Social support & 3.63 & 0.68 \\
\hline General satisfaction & 3.14 & 0.74 \\
\hline Physical and mental wellness & 3.13 & 1.05 \\
\hline Lack of work overload/free time & 2.78 & 1.04 \\
\hline
\end{tabular}

Non significant differences between males and females.

Data showed as mean \pm standard deviation or as number and percentages.

${ }^{a}$ Family APGAR valid values are between 0 and 2 .

b Total value between 0-10: $\geq 7$ Family function; $<7$ : Family dysfunction.

'Valid values for the Ruiz y Baca questionnaire are from 1 to 5, higher punctuation means better quality of life.

Perhaps the many years of caregiving are associated with exhaustion, but in this study neither the years of care nor the age at the start of caregiving proved to be decisive in caregiver's quality of life, as was found by other authors [26].

Other studies have pointed out negative consequences of the two stressors analysed relating to the dependent person compared with such other consequences as overload and mental health $[8,24,27]$. However, with regard to QoL, our data showed that both stressors had practically no consequences. We did not found significant differences either in the QoL of caregivers in relation to age or gender of dependent persons. We therefore agree with other authors who contend that it would make more sense to talk of caregivers of family dependents in general (instead of caregivers of elderly persons or caregivers of dementia patients, etc.), as their emotional problems and vulnerability depend more on the caregiver's own abilities and resources than on the specific set of problems presented by the person being cared for [25-28]. In this respect, the results of this study suggest that family function is an important variable to be taken

Table 4 Multiple linear regression of the global quality of life and its dimensions as dependent variable (Beta values)

\begin{tabular}{|c|c|c|c|c|c|}
\hline \multirow[b]{2}{*}{ Independent Variables: } & \multicolumn{5}{|c|}{ Dependent Variable: } \\
\hline & $\begin{array}{l}\text { GLOBAL } \\
\text { QOL }\end{array}$ & $\begin{array}{l}\text { SOCIAL } \\
\text { SUPPORT }\end{array}$ & $\begin{array}{l}\text { GENERAL SATIS- } \\
\text { FACTION }\end{array}$ & $\begin{array}{l}\text { PHYSICAL-MENTAL } \\
\text { WELLNESS }\end{array}$ & $\begin{array}{l}\text { LACK OF } \\
\text { OVERLOAD }\end{array}$ \\
\hline \multicolumn{6}{|l|}{ Related to the caregiver: } \\
\hline Sex & 0.225 & -0.027 & 0.104 & $0.594 *$ & $0.447 *$ \\
\hline Family Function & $0.139 *$ & $0.101 *$ & $0.131 *$ & $0.192 *$ & $0.121 *$ \\
\hline Relationship: spouse & $\begin{array}{c}-0.461 \\
*\end{array}$ & . & $-0.448 *$ & $-0.551 *$ & $-0.607 *$ \\
\hline Relationship: Son/daughter & & $0.464 *$ & & & \\
\hline Relationship: Grandchild & & $0.857 *$ & & & \\
\hline \multicolumn{6}{|l|}{ Related to the dependent: } \\
\hline Sex & 0.049 & -0.110 & 0.142 & 0.176 & -0.204 \\
\hline Cognitive damage (Pfeiffer Test) & & & & & 0.376 \\
\hline $\begin{array}{l}\text { Level of functional dependence } \\
\text { (Barthel I.) }\end{array}$ & & & & & $-0.409 *$ \\
\hline
\end{tabular}

QOL: quality of life

$* \mathrm{p}<0.05$ 


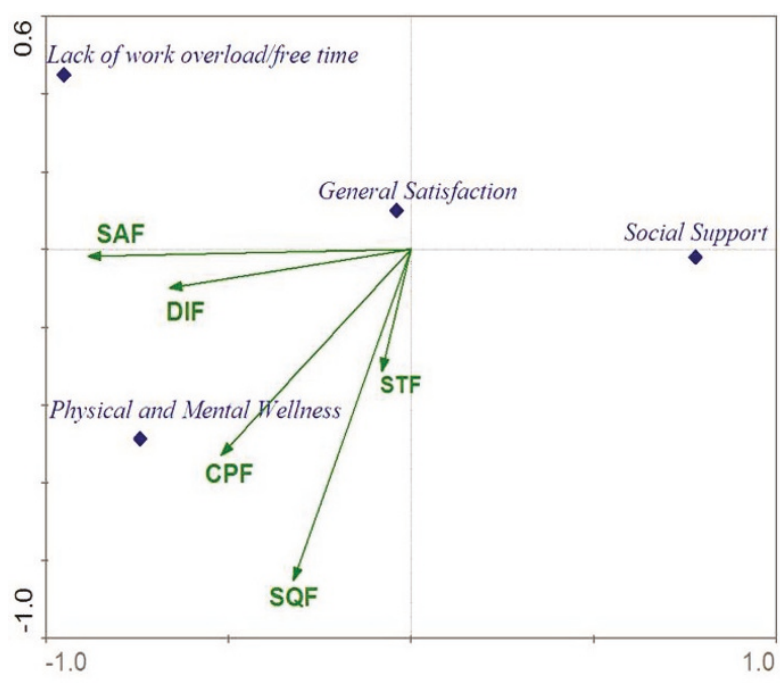

Figure 1 Distribution diagram resulting from studying the influence of every APGAR questionnaire item on the caregivers' Quality of Life using Canonical Correspondence Analysis (CCA). SAF: Are you satisfied with the help that you received from your family?, CPF: Do you talk with your family about your household problems?, SQF: Do you feel that your family loves you?, STF: Are you satisfied with the time that you and your family share together?, DIF: Do you discuss with your family about important decisions that affect the whole family?

into account. A dysfunctional family represents a significant vulnerability factor which affects the caregiver's QoL as well as the quality of care. Chronic disease and, above all, dependence could affect the family and make it dysfunctional $[1,29]$. A negative characteristic of the dysfunctional family is that conflicts grow as communications decline or disappear entirely. The results of this study suggest that those caregivers who make important decisions together with their family are the ones who feel a better state of physical and mental well-being. These results support what has been found by other authors who state that when the decision to become a caregiver is taken on one's own initiative, the fact of being a caregiver may be associated with a greater probability for positive effects related to the care $[27,30,31]$.

This study has some limitations. We should have in mind that we have not used tests specifically designed for family caregivers when evaluating both the QoL and the family function. However, we consider that, in order to analyse how the QoL of the relatives who have ceased to care for the relatives changes, general tests are preferable [32]. The fact of being a caregiver, unlike those with chronic diseases [2,3,12,23,25-28], for whom numerous specific instruments have been designed [30], is usually a transitory situation, and on the other hand, the caregivers are usually seniors with their own multimorbidities [26,33].

\section{Conclusions}

This research suggest that caregivers' perceived family function is an important variable that should be taken into account in the assessment of the patient/caregiver situation when designing the care plan for both of them. In conclusion, we found an association between family functionality and caregivers' QoL. This relation holds for both for the global measure of QoL and for each of its four individual dimensions.

\section{Acknowledgements}

The preparation of this article was supported by grants from the Health Department of the Junta de Castilla and León to the project "Attention to the primary caregiver of dependent relatives: a community intervention"; Carlos III Health Institute (RETICS RD06/0018/0027); Castilla and León Regional Health Authority (project GRS 270/A/08) and the Spanish Ministry of Science and Innovation (PSI2009-08132). Study sponsors had no role in the study design, in the collection, analysis and interpretation of data, in the writing of the manuscript, and in the decision to submit the manuscript for publication.

\section{Author details}

'Unidad de investigación del Centro de Salud de La Alamedilla. Salamanca. España. ${ }^{2}$ Unidad de Investigación de Desarrollo Humano (UNIDESH). Universidad de Carabobo. Maracay. Venezuela. ${ }^{3}$ Departamento de Psicología, Facultad de Ciencias de la Salud, Universidad ReyJuan Carlos, Alcorcón (Madrid), Spain. ${ }^{4}$ Departamento de Estadística. Universidad de Salamanca. Salamanca. España.

\section{Authors' contributions}

Conception of the idea for the study: ERS and LGO. APP and DAP

Development of the protocol, organization and funding, participated in the interview. MCP participated in the design of the study and performed the statistical analysis. ALB and MAG participated in its design and coordination and helped to draft the manuscript. Writing of the manuscript: ERS and LGO All the authors have read the draft critically, to make contributions, and have approved the final text.

\section{Competing interests}

The authors declare that they have no competing interests.

Received: 28 September 2010 Accepted: 15 April 2011 Published: 15 April 2011

\section{References}

1. Glozman J: Quality of Life of Caregivers. Neuropsychology Review 2004, 14(4):183-197.

2. Muhammad A Zahid, Jude U Ohaeri: Relationship of family caregiver burden with quality of care and psychopathology in a sample of Arab subjects with schizophrenia. BMC Psychiatry 2010, 10:71.

3. Northouse LL, Katapodi MC, Song L, Zhang L, Mood DW: Interventions with family caregivers of cancer patients: meta-analysis of randomized trials. CA Cancer J Clin 2010, 60(5):317-139.

4. Haberstroh J, Hampel H, Pantel J: Optimal management of Alzheimer's disease patients: Clinical guidelines and family advice. Neuropsychiatr Dis Treat 2010, 6:243-253.

5. Lawton M, Moss M, Kleban MH, Glicksman A, Rovine M: A two-factor model of caregiving appraisal and psychological well-being. J Gerontol 1991, 46(4):181-189.

6. Pearlin L, Mullan JT, Semple SJ, Skaff MM: Caregiving and the stress process: an overview of concepts and their measures. The Gerontologist 1990, 30(5):583-594.

7. Schalock R: La calidad de vida como agente de cambio: oportunidades y retos. In: Rompiendo Inercias Claves para avanzar. In Jordan, de Urries Vega, FB.. 1 edition. Edited by: Verdugo M. Salamanca. Spain.: Amaru; 2006:543. 
8. Pinquart $M$, Sorensen $S$ : Correlates of physical health of informal caregivers: a meta-analysis. J Gerontol B Psychol Sci Soc Sci 2007, 62(2):126-137.

9. Pinquart M, Sorensen S: Associations of stressors and uplifts of caregiving with caregiver burden and depressive mood: a meta-analysis. J Gerontol B Psychol Sci Soc Sci 2003, 58(2):112-128.

10. Daaleman TP, Frey BB: The Spirituality Index of Well-Being: a new instrument for health-related quality-of-life research. Ann Fam Med 2004, 2(5):499-503.

11. Losada A, Perez-Penaranda A, Rodriguez-Sanchez E, Gomez-Marcos MA, Ballesteros-Rios C, Ramos-Carrera IR, Campo-de la Torre MA, Garcia-Ortiz L: Leisure and distress in caregivers for elderly patients. Arch Gerontol Geriatr 2010, 50(3):347-350.

12. Perez Penaranda A, Garcia Ortiz L, Rodriguez Sanchez E, Losada Baltar A, Porras Santos N, Gomez Marcos MA: Family function and the mental health of the caregiver of dependent relatives. Aten Primaria 2009, 41(11):621-628.

13. Bellon Saameno JA, Delgado Sanchez A, Luna del Castillo JD, Lardelli Claret P: Validity and reliability of the family Apgar family function test. Aten Primaria 1996, 18(6):289-296.

14. Ruiz M, Baca E: Design and validation of the Quality of Life Questionnaire (ccv). A Generic Health-related perceived Quality of Life Instrument. European Journal of Psychological Assessment 1993, 9:19-32.

15. García-Montalvo Jl, Rodriguez L, Ruiperez I: Validación del cuestionario de Pfeiffer y la escala de incapacidad mental de la Cruz Roja en la detección del deterioro mental en los pacientes externos de un servicio de geriatría. Rev Esp Geriatr Gerontol 1992, 27:129-133.

16. Mahoney Fl, Barthel D: Functional evaluation: The Barthel Index. Maryland State Medical Journal 1965, 14:56-61.

17. Ter Braak C: Canonical correspondence analysis: a new eigenvector technique for multivariate direct gradient analysis. Ecology 1986, 67:1167-1179

18. Ter BRAAK C: CANOCO - a FORTRAN: Program for Canonical Community Ordination by (Partial) (Detrended) (Canonical) Correspondence Analysis (Version 2.0). Wageningen; 1988.

19. Ter BRAAK C: CANOCO - an extension of DECORANA to analyse species environment relationships. Vegetatio 1988, 75:159-160.

20. Ter BRAAK C: Update Notes: CANOCO version 3.1. Wageningen 1990

21. Mitrani V, Lewis JE, Feaster DJ, Czaja SJ, Eisdorfer C, Schulz R, Szapocznik J: The role of family functioning in the stress process of dementia caregivers: a structural family framework. Gerontologist 2006, 46(1):97-105.

22. Zarit SH: Family care and burden at the end of life. CMAJ 2004, 170(12):1811-1812

23. Hirokazu A, Nagatsuka M, Hirai K: The relationship between health-related quality of life and social networks among Japanese family caregivers for people with. Disabilities. BioPsychoSocial Medicine 2008, 2:17.

24. Vitaliano P, Russo J, Young HM, Teri L, Maiuro RD: Predictors of burden in spouse caregivers of individuals with Alzheimer's dise. Psychol Aging 1991, 6(3):392-402.

25. Gottlieb B, Wolfe J: Coping with family caregiving to persons with dementia: A critical review. J Aging \& Mental Health 2002, 6(4):325-342.

26. Sewitch MJ, Yaffe MJ, McCusker J, Ciampi A: Helping family doctors detect vulnerable caregivers after an emergency department visit for an elderly relative: results of a longitudinal study. BMC Family Practice 2006, 7:46.

27. Lopez J, Crespo M, Zarit SH: Assessment of the efficacy of a stress management program for informal caregivers of dependent older adults. Gerontologist 2007, 47(2):205-214.

28. Vedhara K, Shanks N, Wilcock L, Lightman SL: Correlates and predictors of self-reported psychological and physical morbidity in chronic caregiver stress. Journal of Health Psychology 2001, 6:101-119.

29. Heru $A$, Ryan $C E$, lqbal $A$ : Family functioning in the caregivers of patients with dementia. J Geriatr Psychiatry 2004, 19:533-537.

30. Koch T, lliffe S: The EVIDEM-ED project. Rapid appraisal of barriers to the diagnosis and management of patients with dementia in primary care: a systematic review. BMC Family Practice 2010, 11:52.

31. Edwards B, Ung L: Quality of life instruments for caregivers of patients with cancer: a review of their psychometric properties. Cancer Nurs 2002, 25(5):342-349.

32. Arostegui Ml, Núñez-Anton V: Aspectos Estadísticos del Cuestionario de Calidad de Vida relacionada con la salud Short Form-36 (SF-36).

Estadística española 2008, 50(167):147-192.
33. Bayliss EA, Ellis JL, Steiner JF: Barriers to self-management and quality-oflife outcomes in seniors with multimorbidities. Ann Fam Med 2007, 5(5):395-402.

\section{Pre-publication history}

The pre-publication history for this paper can be accessed here: http://www.biomedcentral.com/1471-2296/12/19/prepub

doi:10.1186/1471-2296-12-19

Cite this article as: Rodríguez-Sánchez et al:: Relationships between quality of life and family function in caregiver. BMC Family Practice 2011 12:19.

\section{Submit your next manuscript to BioMed Central and take full advantage of:}

- Convenient online submission

- Thorough peer review

- No space constraints or color figure charges

- Immediate publication on acceptance

- Inclusion in PubMed, CAS, Scopus and Google Scholar

- Research which is freely available for redistribution 